\title{
The Need for Effective Leadership in Talent Management in Mauritius
}

\author{
Nirmal Kumar Betchoo \\ Université des Mascareignes, Arianne St, Beau Bassin - Rose Hill, Mauritius \\ E-mail address: betchoonirmal@yahoo.com
}

\begin{abstract}
The importance of linking leadership to talent management is a priority for the Mauritian economy at a time when the economy shifts from the industrial and labour-intensive sector to a services and knowledge-based economy. There is a necessity to link leadership to talent management where local managers are in need of improving their leadership abilities and develop the talent that their organisations may in turn depend upon. It is not merely learning or getting trained in leadership that matters but, more importantly, the need to generate talent from effective leadership strategies. This research article firstly explains the importance of leadership linked with talent. The text then focuses on innovative practices that selected Mauritian companies have undertaken and where talent leadership matters. From this standpoint, the researcher selects effective leadership strategies that might be much needed based from practices that are successful abroad and have positively impacted on the international context. The research emphasises new coaching methodologies linked with the development of leadership talent. Techniques like 'coaching outside in coaching inside out', 'onboarding', 'pivotal leadership', 'reinforcement coaching', are just new approaches that differ from traditional orientation and that are also much relevant in developing leadership talent in the current and future economic conjecture of Mauritius. They have to be adapted to the Mauritian context. Though the research is not exhaustive and is more focused on qualitative than quantitative interpretation, it sheds light onto the fast-developing concept of talent management in business organisations and the need to link leadership in a more conclusive manner.
\end{abstract}

Keywords: leadership; leadership strategies; talent management; Mauritius

\section{INTRODUCTION}

Leadership has a major contribution to contemporary talent management. The worldwide economic crisis has prompted the need for stronger leadership and has made talent management a business priority. It has also formed new realities for organisations and set new precedence in relation to talent management and development [1]. Autocratic leaders - those who just give directives without consulting employees and use an overly directive approach to leading employees - have little or no role in developing talent in the firm. This is because autocratic leaders make decisions without consulting the group, people in the group may dislike that they are unable to contribute ideas and hence develop talent [2]. Democratic leaders, on the other hand - those who are at the other end of the spectrum-Continuum of leadership theory - are liable for effective leadership through the transmission of values, support and deserving help to 
all their employees. They keep listening to their employees, empathise with them, offer the right environment to work and develop talent in the company, and ultimately get the best from managing talent. Researchers have found that this learning style is usually one of the most effective and lead to higher productivity, better contributions from group members, and increased group morale [3].

This research examines the importance of relating leadership to talent management in Mauritius, an island-economy in the South-Eastern part of the Indian Ocean which is now stepping into a knowledge based and services-oriented economy with intentions of developing several pillars namely the ocean-based economy. To achieve the desired objective of becoming a high-income economy, the need for talent leadership is much desired in the present context. A change in mind-set, a different vision combined with strategy and effective leadership could be those stepping stones to the next level of development.

\section{LEADERSHIP IN TALENT MANAGEMENT IN MAURITIUS}

Leadership is the key factor leading to the development of talent. In the Mauritian context, it is particularly the new or emerging sectors that source talent and need high calibre leaders. Companies that work with the external environment will need managers who adopt the best leadership practices in order to maximise the effectiveness of their human capital through the development of talent.

What it means in this context is that local leaders should find out environments that are favourable to the development of talent. Employees can be exposed to new learning techniques, learn a lot from seminars or conferences where they are confronted to experiences from outside managers and leaders. It is through such exposure that leaders will be able to develop or further the potential of their workers. Leadership theory has its say in developing talent equally. If one refers to the Hershey Blanchard Situational leadership theory, he will come to know that leaders who encourage participation and delegation when their employees develop maturity, are more liable to develop the talents of their workers. A good leader develops "the competence and commitment of their people so they're self-motivated rather than dependent on others for direction and guidance" [4].

In the Mauritian context, it is usually difficult to think critically of having the genuine or valued leadership from managers since the work environment looks more for compliance than the development of talent from the workers. Routine work will not disclose the potential of the worker in the same way as compliance.

Leaders' unpredictability does not imply inconsistency - they have to be consistent in their philosophy but must have the ability to think out of the box [5]. This expression may add value to leadership in the field of talent management. It does not merely mean that leaders have to show an extrovert approach to work or simply let lose the organisation by giving too much freedom to their employees. It is rather useful to think how leaders could compel their employees to learn better, improve themselves, overcome their weaknesses, and build up strengths so that their employees intrinsically develop the thirst for learning and seeking talent. This might also break up the day-to-day routine style of work and promote a more conducive work atmosphere. Hence, democratic leaders with a clear intent of leadership and those who genuinely practise leadership will be those who first pass the post.

With a plethora of leadership training programmes available in Mauritius with the contribution of international experts, it is positively thought that leadership could be essential 
to the development of talent in Mauritius. It depends how far the transmission of values and experiences will benefit the workers and positively contribute to their talent management.

\section{1. The need for leaders in talent management}

The talent management game has changed. Slower economic growth combined with a scarcity of talent to fill crucial positions, the advent of social networking and a new generation of digital natives, and increased expectation from the top, mean that the days of transactional HR have long passed. HR leaders want a seat at the strategic table and CEOs want to give it to them. But to be able to make this leap from transactional to strategic, HR leaders need to put greater focus on tools, process and integration and stop addressing talent management without proper consultation. Leadership development is no longer a classroom event; it is now a blended exercise between classroom and real business problems [6].

\section{2. Leadership and Talent: A Priority for Mauritian Companies}

Talent management is increasingly becoming a priority for companies and CEOs have new, more strategic expectations of their HR leadership. At the same time, HR leaders strive to be seen as more than transactional contributors and push for a seat at the executive planning table. To elevate their roles and present CEOs with the thoughtful, proven talent intelligence demanded, HR leaders will need to make systems integration and clean, consistent data greater priorities. There is a strong internal drive, not just within HR, but also within the entire organisation to bring current talent to the next level of leadership. The urgency lies within internal transformation, driving competitiveness and the organisation's achievement towards its strategy and goals [7].

\section{3. Leadership Development}

Most organisations have some kind of leadership development programme in place. Very few have the right kind. All too often, the focus is on acquiring new skills, which may instantly become obsolete with the smallest shifts in technology, market behaviour, or business strategy. Today's rapidly changing world calls for a more contextual approach. More and more leaders are coming to realise that building a strong pool of talent is central to their company's success. And more and more, they are coming to realise that they have a critical role to play in making that happen. Nothing less than the company's fortunes are at stake: For the next two decades at least, a company's ability to attract, develop, excite and retain talent will be a major competitive advantage [8].

Training companies can collaborate to create leadership development solutions that improve company valuation and change people's lives. They do this by anchoring - not just aligning - to the organisation's strategy, mission, culture, and purpose. They also put equal weight on personal, team, and organisational development - prompting progress and momentum on all levels. Leaders with a talent mind-set make talent management a top priority for themselves and their leadership teams. They understand that it can't be delegated, so they commit a major part of their time and energy to strengthening their talent pool and helping others in the company strengthen theirs. They see talent management as a central and critical part of their own job as a leader [9].

\section{4. The value of effective leadership development: Case Examples in Mauritius}

The benefits of having an effective leadership development program are well documented. Studies show that differences in the quality of executive leadership explain an organisation's performance. Much of the talent management process is centred in the development 
of the individuals concerned. In order for them to progress through the organisation to fulfil their organisation's ambitions, they need to have a range of learning and development experiences to prepare them for their roles [10].

Additionally, most ambitious growth-focused organisations are currently pursuing or considering a strategic shift - a change to their core business model that provides fuel for their continued growth, marketplace relevance, and financial health.

Here are some examples of strategic shifts from a number of Mauritian companies:

a) British American, an insurance company operating in Mauritius since 1967, is establishing a series of distribution partnerships and developing a differentiated sales force that captures increased consumer's mind share and time share.

b) ENL group, one of the country's largest private conglomerate, pursues relentlessly a corporate social responsibility programme enabling wider participation of the Mauritian community to get engaged with the group's efforts and activities. This has yielded positive responses to the company.

c) Mauritius Post Ltd, created under a fusion of the Mauritius Postal Service and the Post Office Savings Bank since the new millennium is now a pro-active organisation providing a one-stop service by offering new services like the payment of national pensions in Mauritius, the payment of utility bills, fines, taxes besides its traditional postal services.

d) The Mauritius Revenue Authority (MRA) attempts to improve its performance by climbing the value chain, providing customised online service, and pursuing sources of more strategic, longer-term, and higher-quality revenue.

e) The Ministry of Education and Human Resources is actually in the process of providing tablets to secondary level students in Mauritius in order to bridge the gap between classroom learning and the fast developing communications sector. Learning platforms evidence a change in perception from the government but also leadership that is more open to progress and development.

But not all such shifts come to fulfilment, for many organisations. For some reasons, there is a well-documented gap between vision and execution. Leadership development can be one of the driving forces in closing this strategy-execution gap, getting leaders closer to their vision of the future and realising the potential in their organisation and people. Leadership development is defined as the expansion of a group's capacity to produce direction, alignment, and commitment in contrast to leader development which is the expansion of a one's ability to be effective in leadership roles and processes [11].

\section{5. Growing top talent for the future}

Effective leaders drive solutions to organisational problems. They do so in a way that is consistent with and reinforces the organisation's mission. The best leadership development programs focus not only on building individual leadership skills but also on aligning leader behaviours to organisational goals and objectives [12]. They ensure systems, processes, and structures are in place to provide leaders with the tools they need to achieve desired results.

The figure below displays the various levels whereby leadership development could be aligned with organisational goals. 


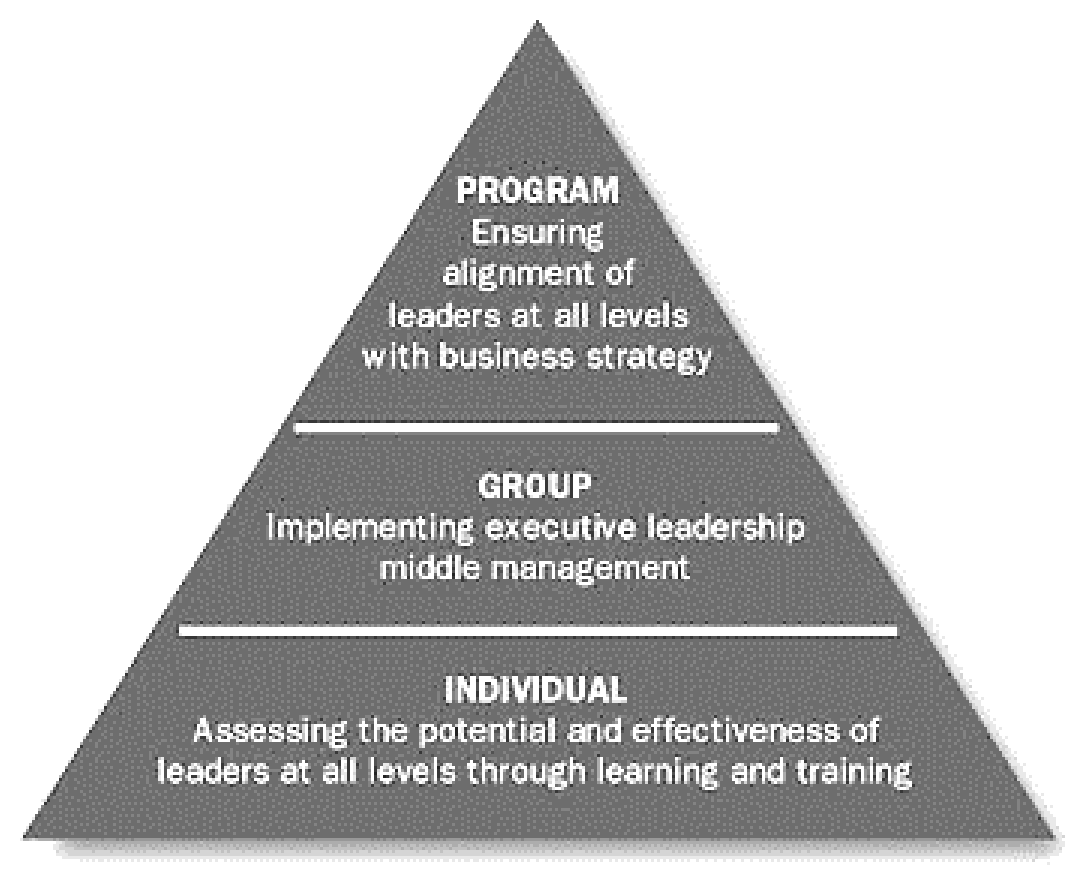

Figure 1. Results-focused leadership development

Source: boozallen.com

\section{6. Application of the results-focused leadership development model to Mauritian companies}

At the lowest level of the pyramid, it would be important to see how managers in Mauritius could be assessed in terms of their potential or aptitudes. Learning and training would be an important factor to assess namely today's ongoing practice of lifelong learning both academically and at the workplace.

Secondly, middle management leadership should be emphasised. Local companies might have given too much importance either to top managers and low-level employees but the importance of middle and line managers cannot be overcome. It is at this level that Mauritius would need fully developed leaders. Porter, in his unique seminar in Mauritius, stated that the next step for the country's development is to make leaders think more strategically and that quality was an important factor in leadership development in the country [13].

The final concern would be the alignment of leadership development with business goals. In a bid to making Mauritius shift from an upper middle-income to a high income economy, government emphasises the need for effective leadership and talent. In its pursuit to become a high-income economy, Mauritius is actively encouraging foreign talents, know-how and investment into the country [14]. Obviously, there should also be focus on developing talents from within and these must fit in both the vision of the country and that of the firm.

\section{7. A Selection of leadership strategies linked with Talent Management}

From the ideas developed above, a selection of leadership strategies are provided below with the objective of getting more specific into what leaders could be developed so that a range of talents could be identified. Some examples are sought from existing companies via their websites but they are re- adapted to the Mauritian context. 


\section{7. 1. Executive on boarding}

Executive on boarding deals with acquiring, accommodating, assimilating and accelerating new leaders into the organizational culture and business. Effective on boarding strategies provide a fast track to meaningful, productive work and strong employee relationships and are tailored specifically to the needs of the individual. Executive on boarding should be strategic, so that it not only prevents executive derailment, but expedites the executive's contribution to optimize strategic achievement [15].

Table 1. Comparison between Executive on boarding and traditional Orientation Source: Office of Personnel Management, USA.

\begin{tabular}{ll}
\hline Onboarding & Orientation \\
\hline Strategic with an impact on bottom-line results & Operational \\
\hline Evolving and progressive & Traditional \\
\hline An ongoing process & An event \\
\hline $\begin{array}{l}\text { Used for transferred and promoted employees, } \\
\text { as well as new hires }\end{array}$ & $\begin{array}{l}\text { Is most often limited to } \\
\text { new employees }\end{array}$ \\
\hline $\begin{array}{l}\text { Delivers information that is unique and } \\
\text { customized to the individual employee and is } \\
\text { generally handed out on an as-needed basis }\end{array}$ & $\begin{array}{l}\text { Delivers information that is } \\
\text { common to all new hires } \\
\text { usually within a classroom setting }\end{array}$ \\
$\begin{array}{l}\text { Has a long-term focus, and can last up to a year } \\
\text { or more }\end{array}$ & $\begin{array}{l}\text { Is a short term program, } \\
\text { typically lasting from one day } \\
\text { to two weeks }\end{array}$ \\
\hline
\end{tabular}

In Mauritius, orientation is the preferred concept especially at the public sector level. on boarding as an executive leadership develop programme could be instrumental for local organisations whereby potential leaders could be able to focus on the long-term benefit of both themselves and their firm.

\section{7. 2. High-Potential and Pivotal Leader Development}

This refers to a useful leadership strategy is developed by Kornferry Associates [16]. They state that when a pivotal job opens up, organisations look toward their talent bench, and it appears somehow ... shorter than expected. There might be people suited up, but few who are truly ready to get into the game. The problem is that organisations overlook readiness - the crucial stage between high-potential identification and actual promotion. While high-potential programs pinpoint talent that will bloom with time, a "ready" candidate has already grown into the bigger role by acquiring the experiences and competencies required [17].

Readiness, like potential, can be measured through a combination of interviews, selfassessments and high-stakes leadership simulations. Simulations, in particular, are a reliable way to surface any shortcomings before putting someone into a mission-critical job [18]. It is this particular area that is of importance to Mauritian leaders but this area might require the contribution of high-flying overseas consultants. 


\section{7. 3. Coaching inside out and outside in}

The best approach to executive coaching is a combination of "inside out" and "outside in." Inside-out coaching focuses on individual drivers: external consultants help leaders gain insight into how their beliefs, values, and motivations drive their behaviours at work. Outsidein coaching focuses on organisation goals: external specialists might help leaders develop a better understanding of what their organisation expects of them and what impact their behaviours have on others [19]. By integrating these two coaching elements, a training company can help leaders transform their performance at a personal, interpersonal, and organisational level. These types of leadership development for talent are in their preliminary stage in Mauritius but need to be developed as the pace of the economic development remains dynamic and progressive with sustained growth rate of $3.5 \%$ [20].

\section{7. 4. Systemic and Enterprise Leadership Coaching}

There are a lot of different theories and models used in coaching as well as in therapy. The therapy model shown below (Figure 2) focuses on visualising the desired state and then helps the patient-here the leader - find steps towards that state. There is no digging down on the root causes, instead just start to change by doing. This model accelerates organisational development through multiple executive coaching engagements that are aligned to the business strategy, building personal, team, and strategic leadership [21].

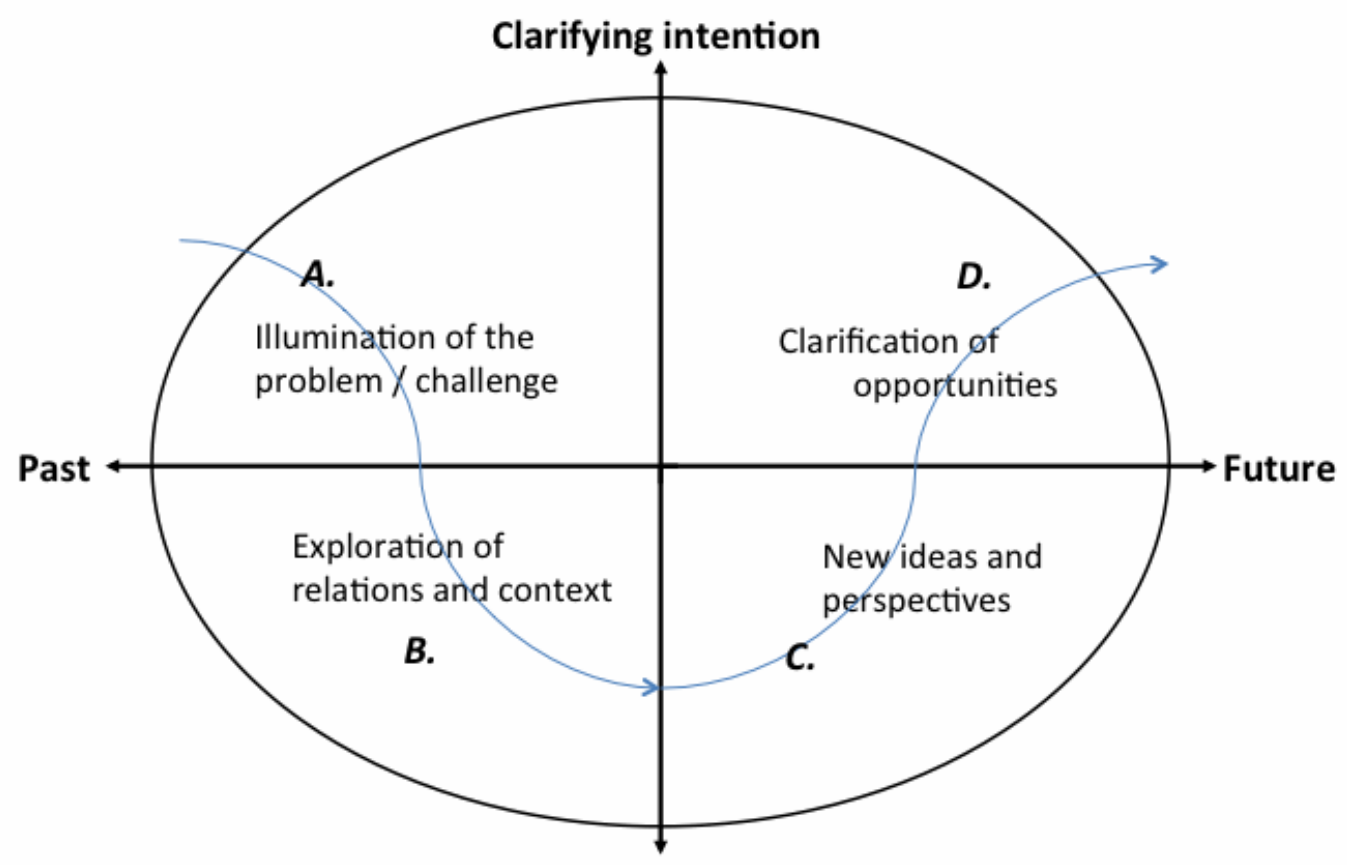

Generative intention

Figure 2. Systemic Coaching approach.

Source: Crisp blog.

In line with systemic coaching for leaders, there are also some useful ones namely: 


\section{Cohort and Team Coaching}

This practice enables small groups of leaders with shared development goals to improve individual and organisational effectiveness while also forming new business partnerships. The issue of partnerships is on the move in Mauritius with takeovers, mergers and strategic alliances particularly in the sugar industry where realignment strategies linked with a reduction in price for exports have led to greater cohesion and cooperation among leaders of different companies. It is also the challenge to converge goals between different leaders for a focused talent based training.

\section{Reinforcement Coaching}

This new leadership training reinforces new leadership behaviours through ongoing coaching and practice. Standalone courses and training will not be useful in Mauritius. Big companies like Lux Resort, SBM Mauritius, Mauritius Commercial Bank, among others, have their own training schools to see that leadership behaviours evolve but also keep improving to align with the local environmental climate.

\section{CONCLUSIONS}

Many successful companies consider their corporate culture as a source of sustainable competitive advantage. They make deliberate efforts to integrate their stated core values and business principles into talent management processes such as hiring methods, leadership development activities, performance management systems, and compensation and benefits programs [22]. This research paper focused on leadership development pertaining to talent development in Mauritius. Trained managers are fully conversant with existing work practices in the country but have little understanding of how talent in leadership would bring the competitive edge. Management gurus like Prahalad, Stiglitz, Peters, Porter, Kotler, among others have appreciated the level of economic development of Mauritius stepping from a monocrop agricultural economy to an industrial one and actually going through the phase of service and knowledge-based economy. Mauritius recognised that without natural resources, its people were its only asset. Maybe that appreciation for its human resources is also what led Mauritius to realise that goal [23]. What the country needs at this stage is leadership development at a higher level to make managers become more pragmatic and critical about future changes and expectations. Shifting from an industrial to a knowledge-based economy as desired by the state, it is clear that talent management will be of greater concern in the country, not only as a buzzword, but as an area of expertise that has to be developed and well addressed to encourage better transition to a new competitive environment where its outcomes can be assessed and appraised deservingly [24]. This is also where talent management seeks the need for effective leadership that should help Mauritius attain higher levels and step into the next economic shift.

\section{ACKNOWLEDGMENTS}

The researcher acknowledges the following concerning the models taken for the purposes of discussion. Boozallen.com for the results-focused leadership development model listed as Figure 1. The US Office of Personnel Management (OPM) for the comparative assessment between on boarding strategy and the traditional orientation model listed as Table 1. Crisp blog for the Systemic leadership coaching approach listed as Figure 2. This novel models have been critical for the development of talent leadership concepts and have been applied to the Mauritian business context. 


\section{References}

[1] Sparkes D. (2008). Leadership and Talent Management, London Management Centre.

[2] Lewin K., Liippit R., White R. K., Journal of Social Psychology 10 (1939) 271-301.

[3] ibid.

[4] Hersey P., Blanchard K. H. (1977) "Management of Organizational Behavior 3-rd Edition - Utilizing Human Resources. New Jersey/Prentice Hall.

[5] Kumar S., Behl N. S. (2012) "Leadership is thinking out of the box" Hindustan Times, New Delhi, March 14, 2012.

[6] Bradshaw P. (2011) "Building Successful Leadership Development \& Talent Management Strategies," HRM Today.

[7] ibid.

[8] Axelrod B., Michaels E., Jones H. (2001). "Talent management: a critical part of every leader's job," Ivey Business Journal.

[9] ibid.

[10] Ashridge Business School (2006). "Developing Future Leaders: The contribution of Talent Management, Fifth International Annual Conference on Leadership," Cranfield, December $14-15,2006$.

[11] McCauley C. D., Brutus S. (1998) "Management development through job experiences: An annotated bibliography," Greensboro, NC: Center for Creative Leadership.

[12] boozallen.com, http://www.boozallen.com/about/doingbusiness/contractvehicles/gmacs/opm-tma/opmtma-human-capital-team/opmtma-hctcapabilities/opmtma-hct-leadership, retrieved on $16^{\text {th }}$ April 2014.

[13] Porter M. (2014). Interview in l'Express, BSP School of Accountancy, Mauritius.

[14] Board of Investment Mauritius (2014). Work \& Live, http://www.investmauritius.com/work-live.aspx, rerieved pon 16th April 2014.

[15] Executive on boarding, Office of Personnel Management, http://www.opm.gov/wiki/training/New-Employee-Orientation.ashx, accessed on 17th April 2014

[16] Crandell S., Hazucha J., Hill C. (2014) "The Readiness Linchpin: Closing the gap between potential and ready-to-promote," Kornferry Associates.

[17] ibid.

[18] ibid.

[19] Skura B. (2009) "Fore thought: Coaching inside out or outside in," The Musoka Sun, $20^{\text {th }}$ August 2009, Page A8.

[20] Economic Indicators (2014). Statistics Mauritius.

[21] Laestadius, A. (2012) "From therapy to continuous improvements". Crisp blogs, Crisp consultants.

[22] Chatman J. A., Cha S. E., California Management Review 45 (2003) 20-34. 
[23] Business Day (2012) Joseph Stiglitz: “The world can learn from the Mauritius Miracle," $6^{\text {th }}$ August 2012.

[24] Betchoo N. K. (2014). People and Talent Management-A Concise Approach, Pan Art publications. ISBN 9781630683207.

( Received 14 April 2014; accepted 21 April 2014 ) 